\title{
Dinâmica do Tebuthiuron em Palha de Cana-De-Açúcar ${ }^{1}$
}

\author{
Performance of Tebuthiuron Applied on Sugarcane Straw
}

\author{
TOFOLI, G.R. ${ }^{2}$, VELINI, E.D. ${ }^{3}$, NEGRISOLI, E. ${ }^{4}$, CAVENAGHI, A.L. ${ }^{5}$ e MARTINS, D. ${ }^{6}$
}

RESUMO - O tebuthiuron é um herbicida residual amplamente utilizado em cana-de-açúcar cultivada no sistema tradicional. Em áreas de cana-crua, o comportamento desse herbicida na palha deixada sobre o solo não é muito conhecido. Para melhor entender esse comportamento, avaliou-se neste trabalho a dinâmica do tebuthiuron aplicado sobre a palha de cana-de-açúcar em diferentes períodos e intensidades de chuvas após a aplicação. Foram conduzidos quatro experimentos instalados em delineamento experimental inteiramente casualizado, com quatro repetições. No primeiro, avaliou-se a interceptação do herbicida tebuthiuron no momento da aplicação sobre 0, 1, 2, 4, 6, 8, 10, 15 e 20 t ha $^{-1}$ de palha de cana-de-açúcar. No segundo, foi avaliada a passagem do herbicida em 5, 10 e $15 \mathrm{t} \mathrm{ha}^{-1} \mathrm{de}$ palha, simulando-se o equivalente a 2,5, 5, 10, 15, 20, 35, 50 e $65 \mathrm{~mm}$ de chuva, um dia após a aplicação (DAA). No terceiro, estudou-se o efeito de diferentes períodos de permanência $(0,1,7,14$ e $28 \mathrm{DAA})$ do tebuthiuron na palha (10 t ha-1) antes da aplicação das mesmas precipitações simuladas no segundo estudo, acrescentando-se ainda mais uma simulação de $20 \mathrm{~mm}$ aos 7 e aos 14 dias após a aplicação do herbicida e das lâminas acumuladas de $65 \mathrm{~mm}$. No quarto, avaliou-se a transposição do herbicida aplicado a $10 \mathrm{t} \mathrm{ha}^{-1}$ de palha, recebendo posteriormente uma lâmina de chuva de água de $20 \mathrm{~mm}$ e, no outro tratamento, uma irrigação de vinhaça de $20 \mathrm{~mm}$, um dia após a aplicação. A quantificação do tebuthiuron foi realizada por cromatografia liquida de alta eficiência (CLAE). Nos estudos de dinâmica observou-se que, quanto maior a quantidade de palha, menor é a quantidade de produto que a transpõe no momento da aplicação. No segundo ensaio, pôde-se observar que, quanto maior a quantidade de palha, menor é a quantidade total extraída na simulação da precipitação. Para o terceiro estudo, os resultados indicaram que, quanto maior o tempo que o produto permanece na palha antes da ocorrência de chuva, menor é a extração total do produto com $65 \mathrm{~mm}$ de precipitação. Para as chuvas de $20 \mathrm{~mm}$ aos 7 e 14 dias após aplicação do herbicida e da lâmina de $65 \mathrm{~mm}$ para cada período, no terceiro ensaio, observou-se extração de quantidades minimas do herbicida. A utilização de vinhaça como chuva simulada proporcionou aumento de $17 \%$ do tebuthiuron lixiviado, quando comparado com a mesma quantidade de chuva simulada com água.

Palavras-chave: herbicida, lixiviação, cana-crua.

\begin{abstract}
Tebuthiuron is a residual herbicide recommended in pre-emergence application for weed control in sugarcane crops. However, the behavior of this herbicide on the straw left on the soil surface of sugarcane areas harvested mechanically without burning is not very known. To better understand tebuthiuron behavior, this study evaluated tebuthiuron dynamics in sugarcane straw at different interval times and different rainfall intensities after such application. Four trials were carried out to using a completely randomized design with four replications. The first trial evaluated herbicide transposition in $0 ; 1 ; 2 ; 4 ; 6 ; 8 ; 10 ; 15$ and 20 tha of $^{-1}$ straw at the moment of

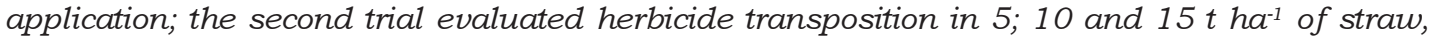
simulating rainfall equivalent to 2.5; 5.0; 10; 15; 20; 35; 50 and $65 \mathrm{~mm}$, one day after tebuthiuron
\end{abstract}

1 Recebido para publicação em 2.6.2008 e na forma revisada em 13.11.2009.

2 Eng-ó-Agr ${ }^{\circ}$., Dr., Dow AgroSciences, Goiânia-GO, <grtofoli@dow.com>; ${ }^{3}$ Prof., Dr., Dep. de Agricultura FCA/Unesp - Fazenda Experimental Lageado, Caixa Postal 237, 18603-970 Botucatu-SP, <velini@fca.unesp.br>; ${ }^{4}$ Eng $^{-}-{ }^{-}$Agr ${ }^{\circ}$., Dr., FCA/Unesp - Fazenda Experimental Lageado, <eduardo.negrisoli@gmail.com>; ${ }^{5}$ Prof., Dr., UNIVAG - Centro Universitário, Av. Dom Orlando Chaves, 2.655 - Cristo Rei, 78118-000 Várzea Grande-MT, <alcavenaghi@uol.com.br>; ${ }^{6}$ Prof ., Dr., Dep. de Agricultura FCA/Unesp Fazenda Experimental Lageado, <dmartins@fca.unesp.br>.

Planta Daninha, Viçosa-MG, v. 27, n. 4, p. 815-821, 2009 
application (DAA). The third trial evaluated the effect of different tebuthiuron permanence times ( 0 ; 1; 7; 14 and $28 \mathrm{DAA})$ on the straw (10 tha $\left.\mathrm{ha}^{-1}\right)$ in function of the same simulated precipitations as in the second trial and $20 \mathrm{~mm}$ of rainfall at 7 and $14 \mathrm{DAA}$. The fourth trial studied transposition of the herbicide applied in $10 \mathrm{t} \mathrm{ha} \mathrm{H}^{-1}$ of straw, with posterior simulated rainfall at $20 \mathrm{~mm}$ using water, and anothertreatment with $20 \mathrm{~mm}$ of simulated rainfall using vinasse one day aftertebuthiuron application (DAA). In all these studies, the quantification of the herbicide was accomplished by HPLC. The dynamics studies showed that the highest amounts of straw had the lowest amounts of transposed herbicides at the moment of the application. The second trial showed, that highest amount of straw provided the lowest total amount extracted in the simulation of maximum precipitation. The third trial results indicated that the higher the period the product remained on the straw before the rain, the lesser is the total amount of the product extracted using $65 \mathrm{~mm}$ precipitation. Even simulating rain of $20 \mathrm{~mm}$ at 7 and 14 DAA, minimum amounts of the product were extracted. Using vinasse as simulated rainfall provided an increase of $17 \%$ of leached tebuthiuron, compared with the same amount of simulated rainfall using water.

Keywords: herbicide; leaching; raw sugarcane.

\section{INTRODUÇÃO}

Na cultura de cana-de-açúcar a colheita sem queima deixa sobre o solo uma espessa camada de palha, que pode superar $20 \mathrm{t} \mathrm{ha}^{-1}$. A palhada e as modificações técnicas necessárias para implementar a colheita mecânica da cultura criaram um novo sistema de produção, denominado de cana-crua.

A palha é apenas uma das barreiras para o uso de herbicidas com ação exclusiva ou preferencial no solo. O acréscimo do teor superficial de matéria orgânica no solo, menos evidente em cana-crua do que em plantio direto, em razão da movimentação mínima no momento da colheita mecanizada associada ao preparo e sulcamento quando da reimplantação da cultura, propicia a adsorção dos herbicidas, limitando a sua eficiência (Negrisoli et al., 2005). Algumas plantas daninhas, como Ipomoea grandifolia e Euphorbia heterophylla, não têm sua germinação inibida pelas quantidades de palha de cana-de-açúcar que normalmente são encontradas em campo (Martins et al., 1999; Velini \& Negrisoli, 2000; Negrisoli et al., 2007b, 2009).

Nas áreas de cana-crua são observadas drásticas reduções na incidência de plantas daninhas gramineas (Velini \& Negrisoli, 2000). Em contraste, altas infestações com Ipomoea sp. e Euphorbia heterophylla têm sido verificadas (Gravena et al., 2004; Martins et al., 1999). Kuva et al. (2007), estudando as comunidades de plantas daninhas em agroecossistema cana-crua, destacam a presença de diversas espécies das famílias Euphorbiaceae e Convolvulaceae.

Correia \& Durigan (2004) estudaram os efeitos da cobertura do solo, com 0, 5, 10 e $15 \mathrm{t} \mathrm{ha}^{-1}$, sobre a emergência de seis espécies de plantas daninhas (Brachiaria decumbens, Digitaria horizontalis, Sida spinosa, Ipomoea grandifolia, Ipomoea hederifolia e Ipomoea quamoclit) e constataram que a cobertura do solo com 5, 10 e $15 \mathrm{t} \mathrm{ha}^{-1}$ inibiu a emergência de plântulas das espécies $B$. decumbens e $S$. spinosa, sendo o mesmo observado para D. horizontalis submetida a 10 e $15 \mathrm{t} \mathrm{ha}^{-1}$. No entanto, para I. grandifolia e I. hederifolia, o número de plantas emersas não diferiu entre as quantidades de palha. Por sua vez, a presença da cobertura morta com palha de cana incrementou a emergência de plântulas de I. quamoclit.

Quando um herbicida é aplicado sobre a palha, é interceptado pela superfície desta e torna-se vulnerável à volatilização e/ou fotólise, até ser lixiviado para o solo (Locke \& Bryson, 1997). O transporte de herbicidas da palha para o solo é dependente das características físico-químicas do herbicida, bem como do período em que a área permanece sem chuva após a aplicação.

O tebuthiuron é um herbicida residual amplamente utilizado na cana-de-açúcar 
cultivada no sistema tradicional, em aplicações de pré-emergência, para controle das principais espécies anuais infestantes da cultura; é também aplicado no sistema de cana-crua, com excelentes resultados de controle (Negrisoli et al., 2005, 2007a).

Devido ao grande uso do tebuthiuron no controle de plantas daninhas na cultura de cana-de-açúcar e à escassez de dados sobre a dinâmica deste herbicida aplicado na palhada deixada sobre o solo no sistema de cana-crua, é de fundamental importância avaliar esse comportamento no sistema. Portanto, objetivou-se avaliar a dinâmica do tebuthiuron em palha de cana-de-açúcar em diferentes quantidades, periodos e intensidades de chuva após a aplicação do herbicida.

\section{MATERIAL E MÉTODOS}

A pesquisa foi conduzida no Núcleo de Pesquisas Avançadas em Matologia (NuPAM) - FCA/Unesp - Botucatu-SP, onde foram realizadas as aplicações do tebuthiuron e as simulações de chuva nas palhas de cana-deaçúcar. As análises do herbicida, para determinação quantitativa, foram realizadas no Departamento de Agricultura - Laboratório de Matologia - FCA/Unesp - Botucatu-SP, utilizando-se um cromatógrafo líquido de alta eficiência equipado com detector espectrofotométrico UV-visivel e coluna cromatográfica Octadecyl $\mathrm{C}_{18}$.

As aplicações do herbicida tebuthiuron e as simulações de chuva foram realizadas com um pulverizador instalado no NuPAM - FCA/ Unesp - Botucatu-SP. A simulação da chuva foi realizada utilizando-se uma bomba hidráulica de pressão constante e acionamento automático, a qual bombeia água armazenada de um reservatório, com capacidade para $1.000 \mathrm{~L}$, até a barra e as pontas de pulverização responsáveis pela formação de gotas de chuva. A barra de simulação de chuva, situada a $1,45 \mathrm{~m}$ de altura em relação à superficie das unidades experimentais, é constituída por três bicos de pulverização TK-SS-20 de alta vazão, espaçados de $0,5 \mathrm{~m}$ e posicionados de forma a propiciar maior uniformidade de precipitação na área aplicada.
Esse sistema foi operado com velocidade de deslocamento de $0,187 \mathrm{~km} \mathrm{~h}^{-1}$, o que correspondeu a 2,5 Hertz no modulador de frequência e pressão de trabalho de $0,81 \mathrm{kgf} \mathrm{s}^{-2}$. Cada lâmina aplicada correspondeu a aproximadamente 2,5 $\mathrm{mm}$ de chuva. Essas especificações proporcionaram a produção de gotas artificiais de chuva com diâmetro mediano volumétrico (DMV) de 1.140 micras, conforme informações do fabricante da ponta de pulverização (Spraying Systems Co.), e cada lâmina aplicada correspondeu a aproximadamente 2,5 $\mathrm{mm}$ de chuva simulada.

A barra de pulverização é constituída por quatro pontas de pulverização XR 11002 VS, espaçadas de $0,5 \mathrm{~m}$ e posicionadas a $0,5 \mathrm{~m}$ de altura em relação à superfície das unidades experimentais. Para as pulverizações do herbicida, o sistema foi operado com velocidade de deslocamento de $3,6 \mathrm{~km} \mathrm{~h}^{-1}$, o que correspondeu a 45,0 Hertz no modulador de frequência, com consumo de calda correspondente a $200 \mathrm{~L} \mathrm{ha}^{-1}$. O equipamento foi operado sob pressão constante de 1,5 bar, pressurizado por ar comprimido. A formulação do tebuthiuron utilizada foi Combine 500 SC suspensão concentrada (500 g i.a. L $\mathrm{L}^{-1}$ ), aplicada na dose de $2,4 \mathrm{~L} \mathrm{ha}^{-1}$.

Para estudo da interceptação do tebuthiuron pela palha da cana-de-açúcar, foram realizados dois testes. No primeiro, utilizaram-se unidades experimentais de $0,016014 \mathrm{~m}^{2}$, nas quais foram colocadas as quantidades de palha de cana-de-açúcar equivalentes a: $0,1,2,5,5,7,5,10,15 \mathrm{e}$ $20 \mathrm{t}$ palha $\mathrm{ha}^{-1}$. No segundo estudo, as unidades experimentais continham $0,04909 \mathrm{~m}^{2}$, com $5,10,15$ e 20 t palha ha ${ }^{-1}$ de cana-de-açúcar. Para os dois testes, os tratamentos tiveram quatro repetições. No primeiro teste, logo após a aplicação, os alvos plásticos previamente posicionados sob a camada de palha foram lavados com volume de $50 \mathrm{~mL}$ de água destilada. No segundo, logo após a aplicação, os funis posicionados abaixo das unidades experimentais foram lavados com volume de 1,0 L de água destilada. As amostras obtidas foram armazenadas para análise no laboratório; posteriormente, o tebuthiuron que transpôs a palha no momento da aplicação foi quantificado.

Planta Daninha, Viçosa-MG, v. 27, n. 4, p. 815-821, 2009 


\section{Desenvolvimento do método analitico}

No desenvolvimento do método analítico para determinação do tebuthiuron em água por cromatografia líquida de alta eficiência (CLAE), foi utilizado o padrão analítico de tebuthiuron fornecido pela Dow Agrosciences, com grau de pureza certificada de 99,6\%.

Quanto ao estudo dos parâmetros analíticos do método cromatográfico tendo em vista sua validação, foi realizada uma calibração da resposta do detector para o herbicida tebuthiuron. Foram preparadas soluções-padrão com solvente metanol e água $(60: 40 \mathrm{v} / \mathrm{v})$ nas concentrações de 0,$1 ; 0,5$; 1,$0 ; 1,5 ; 2,0 ; 2,5 ;$ e $6,0 \mu \mathrm{mL}^{-1}$ a partir de uma solução-estoque de $100 \mu \mathrm{mL}^{-1}$ do padrão analítico preparado com o solvente metanol, devido à sua solubilidade.

\section{Estudo de transposição do tebuthiuron pela palha no momento da aplicação}

Neste ensaio foram determinadas as porcentagens de transposição da palha, pelo herbicida tebuthiuron, no momento da aplicação. Foram estudadas as seguintes quantidades de palha de cana-de-açúcar: $0,1,2,4,6,8,10$, 15 e 20 t ha $^{-1}$ de palha.

A pulverização do herbicida foi realizada na dose de 2,4 $\mathrm{L} \mathrm{ha}^{-1}$ de produto comercial (Combine $500 \mathrm{SC}$ ), contendo $1.200 \mathrm{~g}$ de ingrediente ativo e com volume de calda de $200 \mathrm{~L} \mathrm{ha}^{-1}$, sendo este valor confirmado pela análise da solução da calda por CLAE.

\section{Dinâmica de tebuthiuron em diferentes quantidades de palha de cana-de-açúcar}

Em um suporte móvel de PVC (unidades experimentais), foram colocadas as quantidades correspondentes a 5, 10 e $15 \mathrm{t} \mathrm{ha}^{-1} \mathrm{de}$ palha de cana-de-açúcar. Em seguida, foi realizada a aplicação de tebuthiuron (seguindo os padrões da aplicação anterior).

Um dia após a aplicação (24 horas), as unidades experimentais com palha foram submetidas à chuva artificial de 2,5, 5, 10, 20, 35, 50 e $65 \mathrm{~mm}$, sendo essas precipitações acumulativas. Cada lâmina aplicada correspondeu a 2,5 mm de chuva. Após a realização da simulação de chuva sobre as unidades experimentais, esperou-se cinco minutos antes do início da coleta das amostras, com a finalidade de padronizar a possibilidade de ocorrência de erro, devido ao excesso de água da chuva não embebida pela palhada.

A água que transpôs cada parcela foi medida, coletada e armazenada em geladeira $\left(8 \pm 3{ }^{\circ} \mathrm{C}\right)$, para posterior análise e quantificação do tebuthiuron.

\section{Dinâmica do tebuthiuron com diferentes periodos sem chuva após a aplicação (envelhecimento)}

No suporte móvel de PVC das unidades experimentais, foi colocada a quantidade correspondente a $10 \mathrm{t} \mathrm{ha}^{-1}$ de palha de canade-açúcar; realizou-se a pulverização de tebuthiuron, com as mesmas características das aplicações anteriores.

As parcelas com as palhas foram submetidas a chuvas artificiais aos $0,1,7,14$ e 28 dias após a aplicação (DAA), considerados periodos de permanência do herbicida. Durante esses períodos, as parcelas foram mantidas em casa de vegetação.

\section{Estudo do efeito de vinhaça na dinâmica de tebuthiuron em palha de cana-de-açúcar}

Foi aplicado tebuthiuron a 2,4 $\mathrm{L} \mathrm{ha}^{-1} \mathrm{e}$, 24 horas depois, procedeu-se à lavagem com $20 \mathrm{~mm}$ de vinhaça. Aos 7 e 14 dias após a aplicação, foram realizadas novas chuvas de $20 \mathrm{~mm}$ para todas as parcelas, utilizando-se vinhaça para lavar a palha em substituição à água.

O modelo utilizado para representar a quantidade de tebuthiuron que transpôs a palha em porcentagem do produto aplicado $\left(1.200 \mathrm{~g} \mathrm{ha}^{-1}\right)$ e para estimar a recuperação de herbicida na água de chuva ( $\left.\mathrm{g} \mathrm{ha}^{-1}\right)$ em todos os ensaios foi:

$$
\text { Mitscherlich } \mathrm{Y}=\mathrm{a} *(1-10-\mathrm{c} *(\mathrm{~b}+\mathrm{x}))
$$

em que $Y$ : quantidade do herbicida lixiviado em $\mathrm{g} \mathrm{ha}^{-1}$; e $a, b$ e c: parâmetros da equação, sendo $a$ a quantidade máxima do herbicida retirada pela lâmina de chuva aplicada; $b$, o deslocamento lateral da curva; $c$, a concavidade da curva; e $x$, a quantidade de chuva simulada $(\mathrm{mm})$. 


\section{RESULTADOS E DISCUSSÃO}

\section{Estudo da transposição de tebuthiuron pela palha no momento da aplicação}

Na Figura 1, podem-se observar os dados originais e os ajustados pelo modelo utilizado neste experimento, mostrando o ajuste dos dados e sua precisão.

Pelos resultados obtidos, pode-se observar que as quantidades de palha superiores a $5 \mathrm{t} \mathrm{ha}^{-1}$ utilizadas neste trabalho apresentaram uma interceptação quase que total do herbicida aplicado, com transposições de tebuthiuron, no momento da aplicação, inferiores a $10 \%$ da quantidade de produto aplicada. Esse resultado é semelhante aos obtidos para outros herbicidas pré-emergentes utilizados em cana-de-açúcar (Cavenaghi et al., 2007). Esse fato torna ainda maior a dependência de chuva após a aplicação, pois existe a necessidade de herbicidas pré-emergentes atingirem o solo para que possam atuar de forma eficiente, e a quantidade de palha encontrada sobre o solo em áreas de cana-crua normalmente é superior a $4 \mathrm{t} \mathrm{ha}^{-1}$ de palha.

Resultados obtidos por Velini \& Negrisoli (2000), com aplicação de corante FDC 1 (simulando herbicida) em camadas de palha de 0 a $15 \mathrm{t} \mathrm{ha}^{-1}$, mostram que com apenas $1 \mathrm{t} \mathrm{ha}^{-1}$ somente $35,5 \%$ transpuseram a palha no momento da aplicação. Com 10 e 15 t ha ${ }^{1}$, as porcentagens interceptadas pela palha foram de 99,4 e 99,5\%, respectivamente.

\section{Dinâmica de tebuthiuron em diferentes quantidades de palha de cana-de-açúcar}

Após $65 \mathrm{~mm}$ de chuva nas diferentes quantidades de palha testadas, houve uma transposição de tebuthiuron em torno de $50 \%$ do aplicado; dessa forma, estaria chegando ao solo logo abaixo da palha $50 \%$ da dose do produto, o que poderia resultar em perda do residual do produto no solo.

Na Figura 2 são apresentados os dados ajustados pelo modelo de Mitscherlich. Nesta figura é possivel observar o comportamento da lixiviação do tebuthiuron em cada lâmina de chuva aplicada, para cada quantidade de palha de cana-de-açúcar empregada $(5,10$ e $\left.15 \mathrm{t} \mathrm{ha}^{-1}\right)$.
Até $20 \mathrm{~mm}$ de chuva simulada, os valores de saída de tebuthiuron foram diferentes e seguiram um padrão: quanto menor a quantidade de palha, maior a saída de produto. Depois dos $20 \mathrm{~mm}$ houve uma tendência de os dados serem similares, independentemente da quantidade de palha analisada. Para futuras análises de transposição de tebuthiuron em palha de cana-de-açúcar, $20 \mathrm{~mm}$ de chuva simulada seria suficiente para verificar as principais diferenças de saída de produto em diferentes quantidades de palha. Negrisoli et al. (2007) obtiveram controle excelente de Brachiaria plantaginea, Brachiaria decumbens e Ipomoea grandifolia com tebuthiuron aplicado sobre $5 \mathrm{t} \mathrm{ha}^{-1}$ de cana-de-açúcar, após simulação de chuva de $2,5 \mathrm{~mm}$.

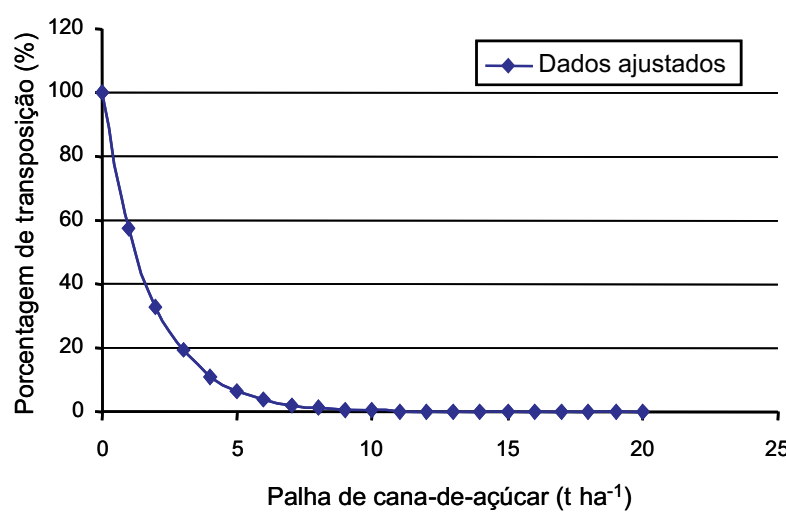

Figura 1 - Dados ajustados para a transposição do tebuthiuron no momento da aplicação em diferentes quantidades de palha.

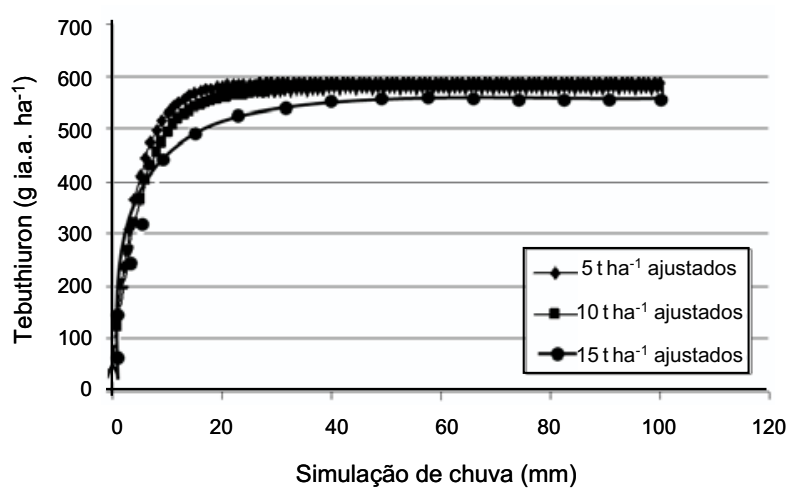

Figura 2 - Lixiviação do tebuthiuron em função de diferentes volumes de chuva simulada e em diferentes quantidades de palha de cana-de-açúcar sobre o solo (dados ajustados pelo modelo de Mitscherlich)

Planta Daninha, Viçosa-MG, v. 27, n. 4, p. 815-821, 2009 


\section{Dinâmica do tebuthiuron com diferentes periodos de permanência na palha (envelhecimento)}

Na Figura 3 são apresentados os dados ajustados pelo modelo de Mitscherlich para a dinâmica de transposição de tebuthiuron nos diferentes períodos de permanência do produto na palha de cana-de-açúcar.

A análise da Figura 3 mostra que houve maior transposição do tebuthiuron ao 0 DAA de permanência do produto na palha, quando comparado com os demais tratamentos. Observou-se ainda uma menor transposição no tratamento de $1,7,14$ e 28 DAA na quantidade de $10 \mathrm{t} \mathrm{ha}^{-1}$ de palha de cana-de-açúcar, na simulação de precipitação de $65 \mathrm{~mm}$.

Os comportamentos das curvas de lixiviação do tebuthiuron nos diferentes períodos de envelhecimento foram semelhantes. No entanto, nota-se relação inversamente proporcional entre a quantidade do herbicida lixiviada e o tempo de envelhecimento: quanto maior o tempo que o tebuthiuron ficar em contato com a palha, menor será sua transposição, independentemente da quantidade de chuva simulada.

\section{Estudo do efeito de vinhaça na dinâmica de tebuthiuron em palha de cana-de-açúcar}

Na Figura 4 são apresentados os resultados das lixiviações obtidas após a lâmina acumulada de $20 \mathrm{~mm}$ de vinhaça e $20 \mathrm{~mm}$ de água.

A utilização de vinhaça como chuva simulada proporcionou uma lixiviação de 760,34 $\mathrm{g} \mathrm{ha}^{-1}$ do total de tebuthiuron aplicado; na utilização de água para simulação de chuva, a quantidade total do produto lixiviado foi de 653,45 $\mathrm{g} \mathrm{ha}^{-1}$. A utilização de vinhaça em vez de água na simulação de chuva proporcionou aumento de $17 \%$ do tebuthiuron lixiviado, quando comparado com a mesma quantidade de chuva simulada com água. Esse tipo de estudo torna-se importante perante a grande utilização de irrigação com vinhaça dentro do sistema produtivo da cana-de-açúcar e a comprovada melhoria nos atributos químicos do solo - fato esse demonstrado por Cannelas et al. (2003).

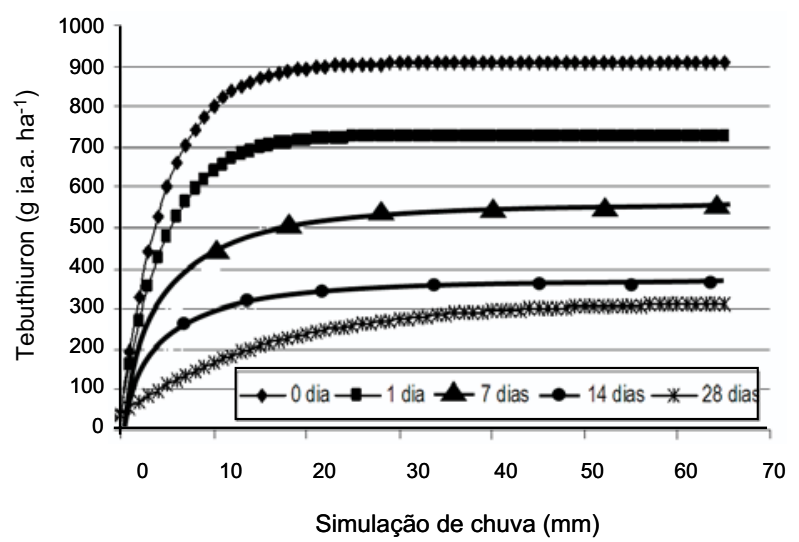

Figura 3 - Lixiviação do tebuthiuron com diferentes intervalos de tempo entre a aplicação e a simulação de chuva (dados ajustados pelo modelo de Mitscherlich).

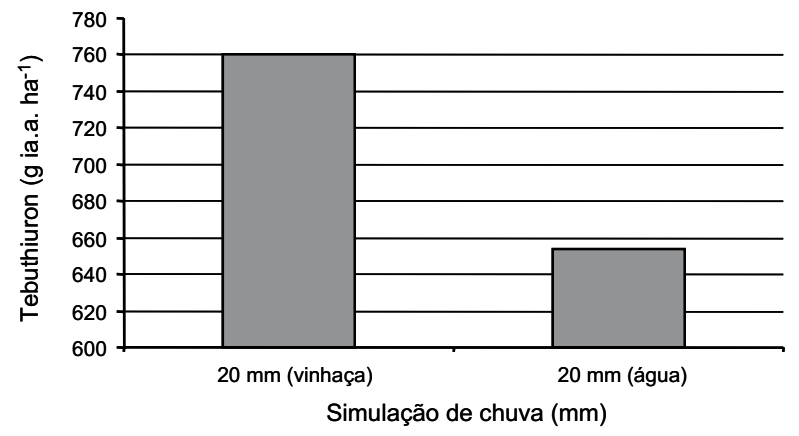

Figura 4 - Quantidade de tebuthiuron lixiviado até a lâmina de $20 \mathrm{~mm}$, para as diferentes quantidades de palha de cana-deaçúcar.

Pelos resultados obtidos, nas condições em que foram realizados os experimentos, pôdese concluir que pequenas quantidades de palha de cana-de-açúcar são capazes de interceptar praticamente toda a calda de aplicação; a primeira chuva e os primeiros $20 \mathrm{~mm}$ de chuva foram fundamentais no processo de carregamento do tebuthiuron para o solo, independentemente da quantidade de palha; e o carregamento do tebuthiuron para o solo foi reduzido com o aumento do intervalo entre a aplicação e a primeira chuva.

\section{LITERATURA CITADA}

CANELLAS, L. P. et al. Propriedades químicas de um Cambissolo cultivado com cana-de-açúcar, com preservação do palhiço e adição de vinhaça por longo tempo. R. Bras. Ci. Solo, v. 27, n. 5, p. 935-944, 2003. 
CAVENAGHI, A. L. et al. Dinâmica do herbicida amicarbazone (Dinamic) aplicado sobre palha de cana-de-açúcar (Saccarum officinarum). Planta Daninha, v. 25, n. 4, p. 831-37, 2007.

CORREA, M. M.; DURIGAN, J. C. Emergência de plantas daninhas em solo coberto com palha de cana-de-açúcar.

Planta Daninha, v. 22, n. 1, p. 11-17, 2004.

GRAVENA, R. et al. Controle de plantas daninhas através da palha de cana-de-açúcar associada à mistura dos herbicidas trifloxysulfuron-sodium + ametrina. Planta Daninha, v. 22, n. 2, p. 419-427, 2004.

LOCKE, M. A.; BRYSON, C. T. Herbicide-soil interaction in reduced tillage and plant residue management systems.

Weed Sci., v. 45, p. 307-320, 1997.

MARTINS, D. et al. Emergência em campo de dicotiledôneas infestantes em solo coberto com palha de cana-de-açúcar.

Planta Daninha, v. 17, n. 1, p. 151-161, 1999.

NEGRISOLI, E. et al. Deposition and leaching of tebuthiuron on sugar cane straw applied with and without alkkyl poyglycoside adjuvnt. J. Environ. Sci. Health. Part B, Pestic. Food Contam. Agric. Wastes, v. B40, n. 1, p. 207-214, 2005.
NEGRISOLI, E. et al. Eficácia do herbicida oxyfluorfen com a cobertura de palha no controle de plantas daninhas. Planta Daninha, v. 27, n. 1, p. 197-203, 2009.

NEGRISOLI, E. et al. Associação do herbicida tebuthiuron com a cobertura de palha no controle de plantas daninhas no sistema de cana-crua. Planta Daninha, n. 3, v. 25, p. $621-628,2007 \mathrm{a}$.

NEGRISOLI, E. et al. Controle de plantas daninhas pelo amicarbazone aplicado na presença de palha de cana-de-açúcar. Planta Daninha, v. 25, n. 3, p. 603-611, $2007 b$.

KUVA, M. A. et al. Fitossociologia de comunidades de plantas daninhas em agroecossistema cana-crua. Planta Daninha, v. 25, n. 3, p. 501-511, 2007.

VELINI, E. D.; NEGRISOLI, E. Controle de plantas daninhas em cana crua. In: CONGRESSO BRASILEIRO DA CIÊNCIA DAS PLANTAS DANINHAS, 22., 2000, Foz de Iguaçu. Palestras... Foz de Iguaçu: Sociedade Brasileira da Ciência das Plantas Daninhas, 2000. p. 148-164. 